\title{
Modeling the dynamic mechanism of the innovative systems self-development
}

\author{
Leonid Baev ${ }^{1}$, Oleg Golikov ${ }^{1}$, and Natalya Pravdina, \\ ${ }^{1}$ High School of Economics and Management, South Ural State University (National Research University), Chelyabinsk, Russia
}

\begin{abstract}
The article is devoted to the creation of efficient economic mechanisms of innovative systems self-development regulation. In the current social and economic conditions stimulating innovative development remains one of the most important tasks of the state economic policy. One of the instruments used to activate the innovative processes is the territories of advancing social and economic development. A special legal regime in such territories provides various preferences for their residents, including tax benefits. The criteria of the preferences provided to the entities are formal, and the management mechanisms of the territory are "indistinct" and subjective. In this regard the development and research of the mechanisms stimulating positive dynamics of economic development according to the actual growth of production efficiency are presented.
\end{abstract}

\section{Introduction}

The problem of achieving sustainable increase in productivity and production efficiency is always relevant for the socio-economic system of any country regardless of the management level. Many economists associate solving this problem with the intensification of investments to innovative technology, often reducing development constraints to the insufficiency of financial resources. While recognizing the importance of investments in real assets as well as the feasibility of increasing such investments in the budgets of developing countries, it is very important to pay attention to the managerial component of the development processes. What proves the importance of management quality is the low developmental dynamics our country had in 2004 through 2014. Over this period, the annual average oil prices rose from $\$ 28.5$ per barrel in 2003 to $\$ 99.5$ per barrel in 2014 , i.e. by $249 \%$. GDP growth amounted to $48.7 \%$, which is below the world average of $49.2 \%$ [1].

The economic crisis of 2014-2016 only worsened the situation. The objective now is to reach the world average economic growth figures by 2019 [2].

It is important to note that it is not possible without activating the stimuli that would intensify economic growth and promote better economic management.

The lack of economic mechanisms for regulating hitech industrial development has been noted before [3, 4]. At the same time, targeted economic benefits of various kinds that are available to special economic zones, tech parks, industrial sites and innovative groups, often do not have any positive effects because they are mostly implemented on formal grounds $[5,6,7,8]$.
We believe that such formal approach is still visible for instance in the concept of establishing the so-called advancing socio-economic development territories.

Territories of advancing socio-economic development, or TASED, are offered as a tool for intensifying innovation processes 'on-site'. In accordance with the Federal Law [9], TASED is a part of a Russian Federation's entity, which features a special legal regime for entrepreneurship, aimed at creating favourable environment to attract investments, accelerate socio-economic development and create comfortable conditions for the population.

A special legal regime includes a wide range of various preferences to the residents of such TASED, with an emphasis on tax reliefs and exemptions from contributions to state non-budgetary funds.

To date, open information sources contain no details about in-depth studies of how efficient and effective the actually existing TASEDs are. When analysing the legislation and management methodology association with TASED, one can conclude these documents describe no clear mechanisms, tools and criteria for the management of TASED. This casts doubt on the possibility to guarantee the expected outcomes.

For instance, [10] suggests that the Presidential Decree on Assessing the Performance of Executive Bodies in the Entities of the Russian Federation [11] will suffice to compensate the lack of methodological recommendations on how the state could assess the performance of TASED.

Analysing the criteria laid down in that Decree as well as the author's proposals the paper[10] reveals the 'indistinct' and subjective nature of such criteria which are aimed at the ease of measurement while offering no

*Corresponding author: natalyf75@mail.ru

(C) The Authors, published by EDP Sciences. This is an open access article distributed under the terms of the Creative Commons Attribution License 4.0 (http://creativecommons.org/licenses/by/4.0/). 
option to objectively converge multiple heterogeneous indicators into an integral criterion.

In this regard, it seems appropriate to develop and research the mechanisms that promote positive economic development; such research should be based on production performance rather than formal grounds. It is the dynamic increase in production performance which we believe is the main sign and objective of innovative development $[12,13]$.

It seems appropriate to search for the solution to this problem by studying enterprise self-development mechanisms while implementing developmentintensifying regulators within the same framework.

The goal of this research is to disclose the essence of the enterprise self-development mechanisms and to substantiate the opportunities for controlling this process in terms of the primary objective of innovative development, which is increase in production performance.

The object of this study is a commercial enterprise. The subject is the self-development mechanism and the impact the intensifying feedback could have on it.

\section{Economic mechanism of enterprise self-development}

Let us analyse how an enterprise could regulate its selfdevelopment; the analysis is to be based on the simplest extended reproduction model. In the absence of credits and where only the corporate tax is taken into account, the extended reproduction model looks as presented in Figure 1.

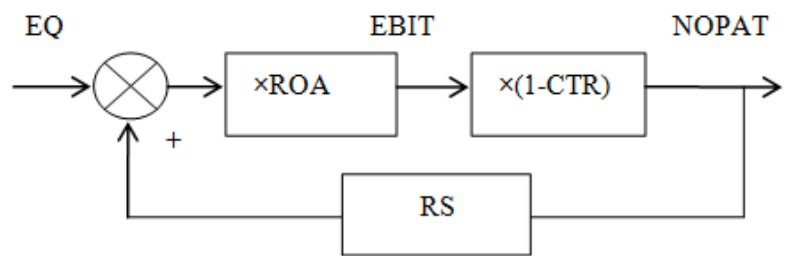

Fig. 1. Extended reproducing model.

This model uses the following abbreviations: EQ for Equity, ROA for Return on Assets, EBIT for Earnings before Interest and Taxes, CTR for Corporation Tax Rate; NOPAT for Net Operation Profit after Tax, and RS for Rate of Savings.

Speaking of self-development of a commercial enterprise, one should note there is a number of positive feedbacks in the extended reproduction mechanism. Given EQ with a certain ROA value, one can obtain an EBIT value. By calculating the CTR-based income tax, we obtain the NOPAT value. Re-investing a portion of NOPAT with a certain RS value results in extended reproduction and enables further innovative selfdevelopment and performance increase. This, in turn, further increases NOPAT and enables further development.

In accordance with this model, the rate of return on invested capital is written as

$$
R O I=\frac{N O P A T}{I_{0}}=\frac{R O A(1-C T R)}{1-R O A(1-C T R) R S}
$$

Where $R O I$ - Return on Investment;

NOPAT - Net Operation Profit after Tax;

$I_{0}$ - Investments;

$R O A$ - Return on Assets;

$C T R$ - Corporation Tax Rate;

$R S-$ Rate of Saving.

Speaking of innovative development, it should be borne in mind that maxing out the innovative potential of a project in particular and of an innovative technology in general is an S-curve rather than linear $[14,15,16,17$, 18]. To refine the model, let us describe this curve with Pearl's formula $[15,18]$, by varying the parameters of which we could handle the specifics of innovative development.

$$
y=\frac{L}{1+a e^{-b\left(t-t_{0}\right)}},
$$

Where $L$ is the upper limit of variable y;

$a$ and $b$ are the positive parameters affecting the curve;

$t$ is time.

Using the S-shaped function of Pearl's formula as a mathematical description allows one to specify how the ROA shall alter change so as to handle to a large extent the specifics of innovative business development.

Figure 2 presents an S-shaped curve showing how the ROA alters as innovations are implemented. The curve is constructed on the basis of the equation (2). The maximum value of return $\mathrm{L}$ equals $25 \%$, whereas the a and $b$ values are chosen so as to obtain a curve with a maximum correspondence to the patterns of innovative development.

Figures 3 and 4 present the dynamics of ROI and ROI growth rate in view of the S-shaped alteration of economic returns.

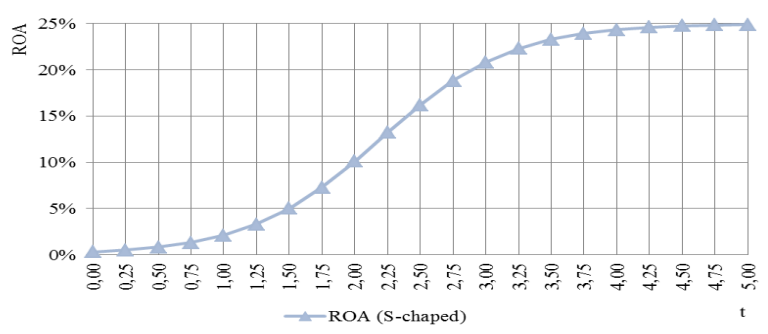

Fig. 2. S-shaped dynamics or ROA.

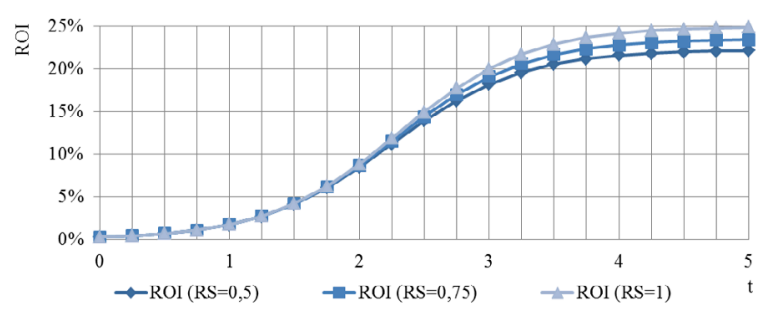

Fig. 3. How ROI alters relative to ROA with a CTR of $20 \%$. 


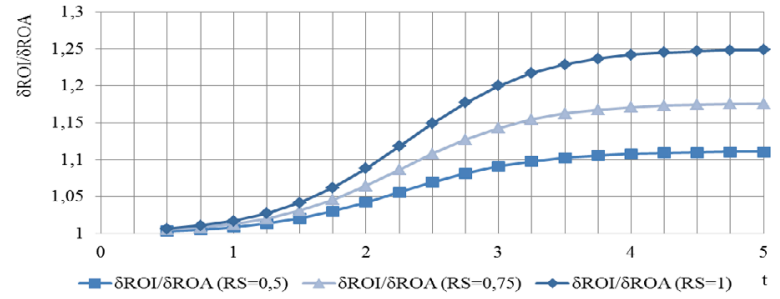

Fig. 4. How ROI increase rate alters relative to the ROA increase rat.

\section{Boosting the innovative development by implementing a dynamic tax regulator}

Simulation results show that under the 'natural' conditions of enterprise self-development, the stimuli and options to boost the innovative self-development are slim. It is, however, possible to control the intensification of innovative development by adding a dynamic corporate tax rate in this model [12].

The functional dependency of the dynamic corporate tax rate (CTRD) is determined on the following grounds. Where the production performance increases at a regular rate, the dynamic regulator should have the strongest impact.

Tax rate is adjustable from $40 \%$ for negative performance increase to $0 \%$ for an increase rate that exceeds the regular values by a margin.

In case the performance increase has a regular value, the corporate tax rate has a rated value of $20 \%$. The curvature of the curve, and thus the impact of the regulator depends on the parameters $a$ and $b$.

Parameter $\mathrm{v}$ describes the innovation performance increase rate as specified by the $\mathrm{S}$-shaped curve, relative to the regular efficiency increase rates. In this model, the regular value of return on assets is $5 \%$ per annum, which roughly corresponds to the world average innovative business development rates.

The equation for the dynamic corporate tax rate curve corresponds to the Pearl equation (2) subject to adjustments necessary to render the economic intension of $\mathrm{CTR}_{\mathrm{D}}$ :

$$
C T R_{D}=C T R_{D, M A X}-\frac{C T R_{D, M A X}}{1+a e^{b(1-v)}}
$$

Where $C T R_{D}$ is the dynamic tax rate;

$a$ and $b$ are the positive parameters affecting the curve;

$v$ is the innovation performance increase rate relative to the regular performance increase rates.

Figure 5 presents dynamic tax rate values for various equation parameters (3).

From the Figure, one can see that where the efficiency increase rate has a regular value, the tax rate has the standard value of $20 \%$. Where the efficiency increases relative to the regular values, the corporate tax rate falls to zero; or it rises to $40 \%$ where the efficiency increase rate is lower.
Integrating the dynamic corporate tax rate in the extended reproduction mechanism adds dynamic positive feedback on the innovative business performance increase rates, which alters the quality of self-development, see Figures 6 and 7.

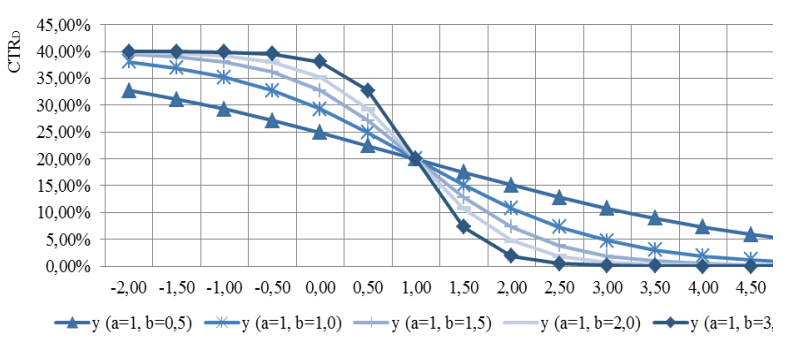

Fig. 5. Dynamic income tax rate at $C T R_{D, M A X}=40 \%$.

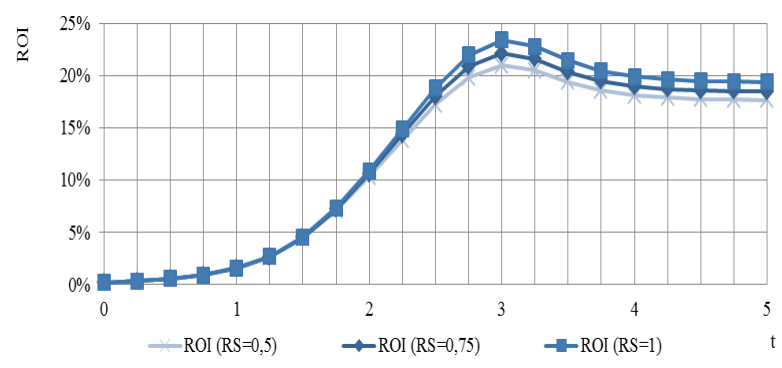

Fig. 6. ROI with the dynamic taxation $(a=1, b=2)$.

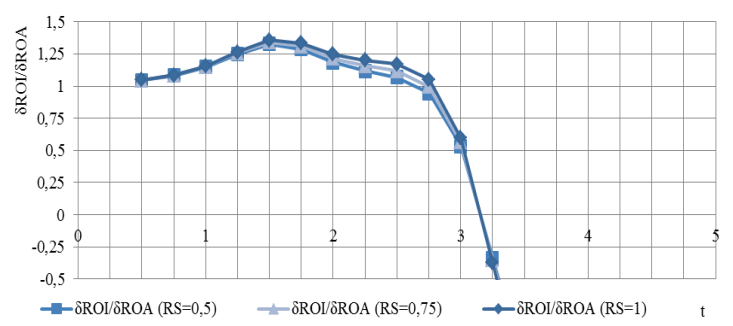

Fig. 7. Rates of growth of the ROI with the dynamic taxation $(\mathrm{a}=1, \mathrm{~b}=2)$.

Comparison of Figures 3, 4 and 6, 7 demonstrates the desired effect of the dynamic regulator. Under dynamic regulation, the ROI increase rate relative to the ROA increase rate is greater until middle of the third year, which creates additional opportunities for selfdevelopment. Then this value drops, which should become an additional stimulus to further promote increases in performance and to incentivize search for ways of innovative development.

It should be noted that the relatively small proportion of corporate tax in the total tax deductions and operating profits of an enterprise makes the regulator less impactful, which is why it is necessary to find a way to increase that proportion.

\section{More impactful tax regulation}

The simplest and the most natural way to make dynamic regulation of intensive self-development more impactful 
is to add other tax channels of an enterprise to that regulator; the TASED concept actually allows that. To assess the feasibility of dynamic regulation of enterprise self-development, let us analyse the overall tax burden of Russian companies.

According to the calculations made by PricewaterhouseCoopers Audit, the total tax burden for Russian companies is about $50 \%$ of their commercial profits $[19,20]$. Commercial profits is income before any taxes [21]. According to PricewaterhouseCoopers Audit, commercial profits of Russian companies equals $175 \%$ of their operating profits, on average [20].

In view of the foregoing, the self-development regulation model looks like in Figure 8.

This model is different from that in Figure 1 because it has a coefficient of 1.75 in the straight chain that converts operating profits into commercial profits; the updated model also has a wider dynamic regulation range with $\mathrm{TR}$ values of $\mathrm{TR}_{\mathrm{D}, \mathrm{MAX}}=100 \%, \mathrm{TR}_{\mathrm{D}, \mathrm{N}}=50 \%$, $\mathrm{TR}_{\mathrm{D}, \mathrm{MIN}}=0 \%$.

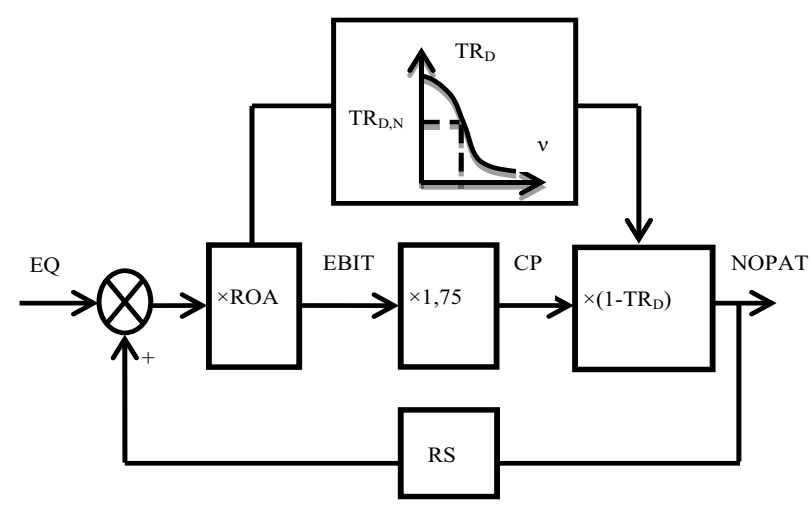

Fig. 8. Model of complete dynamic tax regulation of selfdevelopment. Functional diagram.

Here: $\mathrm{TR}_{\mathrm{D}, \mathrm{N}}, \mathrm{TR}_{\mathrm{D}}$ (Tax Rate) is the dynamic tax rate; $\mathrm{CP}$ is Commercial Profit.

In accordance with Figure 8, return on investments, or ROI, could be written as:

$$
R O I=\frac{1,75 R O A\left(1-T R_{D}\right)}{1-1,75 R O A\left(1-T R_{D}\right) R S}
$$

Thereby the dynamic tax rate will be as follows (Figure 9).

For the comparative assessment of the impact of the regulator, let us analyse three models. The first model employs a constant corporate tax rate of $20 \%$. The second model is a dynamic regulator with a maximum rate of $40 \%$. The third model is the more impactful tax regulator with a maximum rate of $100 \%$. For all three models, let us specify the same S-shaped dynamics of economic return with a maximum value of $25 \%$. The regular return on assets increase is $5 \%$.

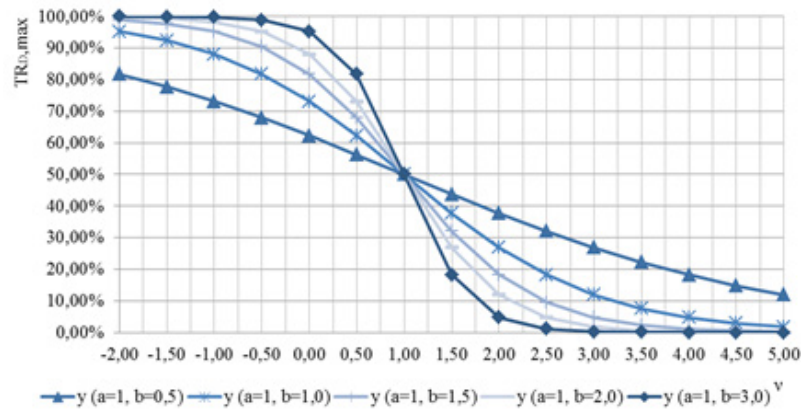

Fig. 9. Dynamic income tax rate at $\mathrm{TR}_{\mathrm{D}, \mathrm{MAX}}=100 \%$.

Figures 10 and 11 present the dynamics of ROA and ROI for all the three models with the rate of savings of 0.5 and 1 .

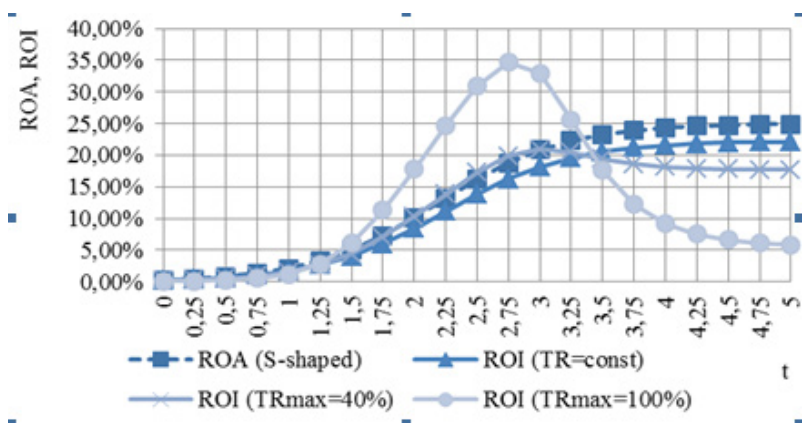

Fig. 10. Alteration of ROA and ROI at $\mathrm{RS}=0.5$.

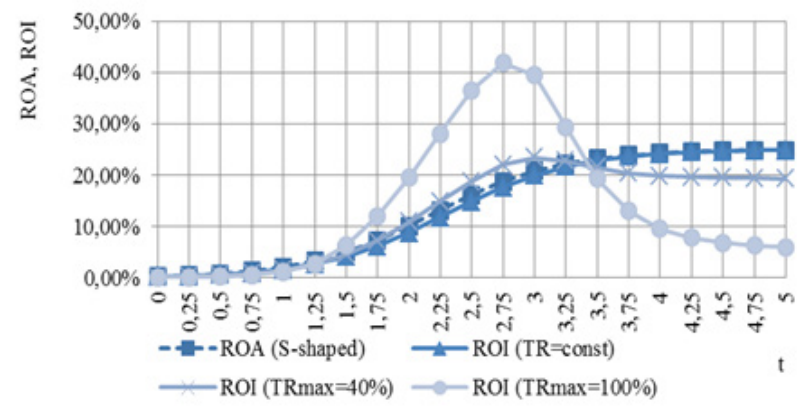

Fig. 11. Alteration of ROA and ROI at $\mathrm{RS}=1$.

As one can see from Figure 10, more impactful tax regulation of the self-development mechanism makes the latter substantially stronger. At a time that corresponds to the middle of the third year, ROI amounts to $16 \%$ in the first model, $20 \%$ in the second model, and almost $35 \%$ in the third model. Setting the rate of savings to 1 , see Figure 11, allows rising the ROI in the third model to approximately $42 \%$ per annum.

The curves in Figures 10 and 11 are constructed for a situation where the regular (or expected) increase in returns is $5 \%$ per annum. Obviously, if we make that value smaller so that it is closer to Russia's average innovative development dynamics, the mechanism under analysis becomes even more impactful, see Figures 12 and 13. 


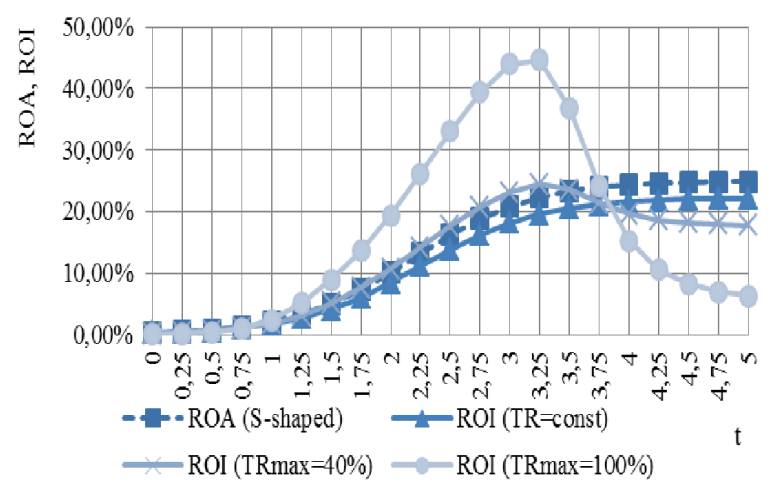

Fig. 12. Alteration of ROA and $\mathrm{ROI}$ at $\mathrm{RS}=0.5$, with a regular ROA increase value of $2.5 \%$ per annum

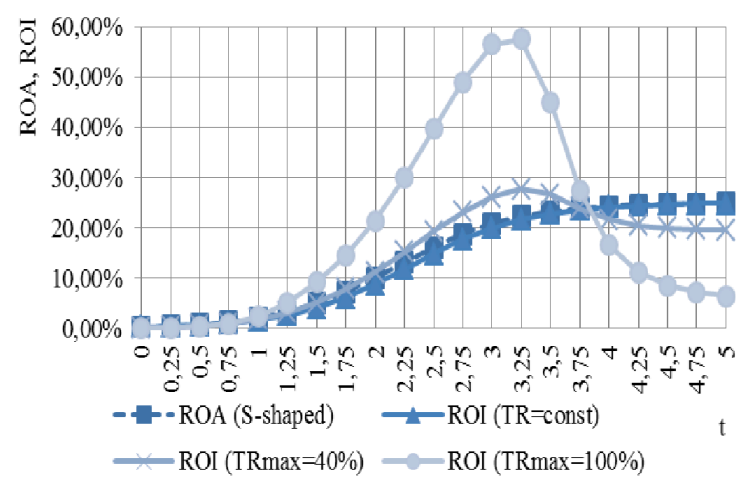

Fig. 13. Alteration of ROA and ROI at RS=1, with a regular ROA increase value of $2.5 \%$ per annum

In conclusion, it should be noted that the regulators proposed not just promote, and create opportunities for dynamic self-development at the stage of innovation implementation; they also determine the appropriateness of switching the enterprise to normal (non-preferential) operation as soon as its innovation capacity is maxed out. We have analysed how the innovation capacity could be maxed out over 3.5 to 4 years; it is at the end of this period that switching to regular taxation becomes appropriate.

\section{Conclusion}

This research has led to the following conclusions. Implementing a dynamic tax regulator of selfdevelopment promotes, and creates additional opportunities for dynamic self-development and accelerated exploitation of the innovative capacities of innovations.

Dynamic regulation of the self-development of innovative systems makes the focused on achieving the primary goal of innovative development, i.e. increasing the production efficiency.

The regulator can be made impactful enough by adjusting the entirety of taxes, which is in line with the conceptual fundamentals of the territories of advancing socio-economic development of the advancing social and economic development.
The work was supported by Act 211 Government of the Russian Federation, contract № 02.A03.21.0011.

\section{References}

1. World countries rates. http://www.ereport.ru/stat.php?razdel=country/.

2. Message of the president for the Federal Assembly.http://www.kremlin.ru/events/president /news/47173.

3. M.A. Omarov, Conversion of the military industrial complex in system of state policy of modern Russia (Moscow, 2010)

4. R.A. Faramazian, Transformation of military economy: $X X$ - the beginning of the 21st century (Nauka, Moscow, 2006)

5. In 10 years the SEZ didn't become the efficient instrument of of the economy supportment. http://audit.gov.ru/press_center/news/26369.

6. Bulletin of Audit Chamber of the Russian Federation.http://audit.gov.ru/upload/uf/fac/fac89 025a3b0198bcddedfb9d1962bec.pdf.

7. Bulletin of Audit Chamber of the Russian Federation.http://www.ach.gov.ru/upload/uf/f33/f 335f242ebb55bf00f87282ee902ab74.pdf.

8. The Audit Chamber has revealed numerous violations during creation of science and technology parks. http://www.cnews.ru/news/top/schetnaya_palata vyyavila_mnogochislennye.

9. The federal law of December 29, 2014 No. 473FZ About the territories of the advancing social and economic development in the Russian Federation (2014)

10. E.A. Myakisheva, Methodological support of the territories of advances social and economic development management (Perm, 2015)

11. About an efficiency evaluation of activities of executive authoroties of subjects of the Russian Federation, Legislation of the Russian Federation (2012)

12. L.A. Baev, Intensive self-organization of economic systems: concept, theory, models (ChGTU, Chelyabinsk, 1992)

13. L.A. Baev, V.E. Shugurov, System approach to definition of an innovation (ChGTU, Chelyabinsk, 1995)

14. U.N. Startsev, S-shaped models of development and technological gaps. http://www.lib.csu.ru/vch/128/010.pdf.

15. Dg. Martino, Technologocal forecasting (Progress, Moscow, 1977)

16. D. Sahal, Technical progress: concepts, models, assessments (Finance and Statistics, Moscow, 1985)

17. S.G. Selivanov, S.N. Poezzhalova, Innovative regularities of development of aviation 
engineering and technologies. http://innov.etu.ru/innov/archive.nsf/0d592545e5 d69ff3c32568fe00319ec1/82425210c23f9c68c325 $7801003189 \mathrm{eb}$ ? OpenDocument.

18. U.A. Salikov, I.N. Bulgakova, Improvement of the model of social and economic systems development.http://econ.vsu.ru/downloads/pub/se conomic/2/salikov.pdf.

19. Paying taxes 2016. http://www.doingbusiness.org/ /media/GIAWB/D
oing\%20Business/Documents/SpecialReports/Paying-Taxes-2016.pdf.

20. Paying taxes http://www.pwc.ru/ru/events/2013/payingtaxes/2-pwc-uk-packman-ru.pdf.

21. Paying taxes 2016.http://www.pwc.ru/en/taxconsulting-services/assets/paying-taxes-2016appendix-1.pdf. 